\title{
Optical methods to study the behaviour of supported metallocene catalysts during olefin polymerisation
}

\author{
Yong-Jun Jang ${ }^{1}$, Kirsten Bieber ${ }^{1}$, Corinna Naundorf ${ }^{1}$, Nikolay Nenov ${ }^{1}$, \\ Markus Klapper ${ }^{1}{ }^{*}$, Klaus Müllen ${ }^{1}$, Daniela Ferrari ${ }^{2}$, Stefan Knoke ${ }^{2}$, Gerhard Fink ${ }^{2}$ * \\ ${ }^{1}$ Max-Planck-Institut für Polymerforschung, Ackermannweg 10, 55128 Mainz, \\ Germany; Fax 00-49-6131-379-100; klapper@mpip-mainz.mpg.de \\ ${ }^{2}$ Max-Planck-Institut für Kohlenforschung, Kaiser-Wilhelm-Platz 1, 45470 Mülheim, \\ Germany; fink@mpi-muelheim.mpg.de
}

(Received: October 29, 2004; published: February 28, 2005)

\begin{abstract}
It is demonstrated that modern optical methods allow for a very fast study of the behaviour of supported metallocene catalysts. By videomicroscopy several polymeric supports functionalised with cyclopentadiene units or poly(ethylene oxide) and poly(propylene oxide) chains and loaded with a metallocene were simultaneously studied. In this example it is shown that this method allows for a direct comparison of different catalysts under identical conditions in a single experiment. In addition by this experiment more detailed information on the behaviour of the supports can be obtained by studying the growth kinetics of single grains. As a second tool, laser scanning confocal fluorescence microscopy (LSCFM) was applied. Using dye-labelled supports LSCFM can be used as a very rapid tool to study the fragmentation of supports. This is demonstrated by 3D images showing the distribution of different support fragments in the polyethylene product particles.
\end{abstract}

\section{Introduction}

For industrial applications of metallocenes, immobilisation of the catalyst is necessary to allow for perfect product control, especially of particle size, density and form of the polyolefin particles. Therefore, many different supports for immobilisation have been investigated. Mainly they are based on inorganic materials but also organic supports have received increasing attention [1-16].

It had been shown that supports have to fulfil several requirements as to control the polymerisation process and to obtain products with a desirable morphology. The carrier has quantitatively to immobilise the metallocene to avoid leaching and reactor fouling during the polymerisation process. Typically the supports have to be particles with an average size of $50-100 \mu \mathrm{m}$ (final particles); however, they should be able to fragment during the polymerisation into $\mathrm{nm}$-sized particles (primary particles).

So far the total course of olefin polymerisation and fragmentation of the supported catalyst as a part of this process have been studied by

a) Büchi reactor kinetic [17-21]: measuring the monomer consumption gives information about the course of the instationary polymerisation rate with time, reaction orders and activation energy. 
b) Bulk polymerisation kinetics in liquid monomer: measuring the polymer formation by means of a heat flow calorimeter leads again to the instationary polymerisation rate, reaction orders and activation energy [22-24].

c) Electron microscopic kinetics: electron microtome sections (scanning electron microscopy and transmission electron microscopy) of the polymerising particles give information about polymer growth, particle fragmentation and particle expansion $[22,17]$.

The results from these investigations led to mathematical models of the total polymerisation process as, e.g., the polymeric flow model, the multi-grain model, and the polymer growth and particle expanding model $[25,26]$.

In this paper we introduce videomicroscopy and laser scanning confocal optical microscopy (LSCFM) as two new optical methods for determining the particle expansion kinetics and particle fragmentation. Videomicroscopy allows the simultaneous observation of many polymerizing particles in situ $[27,28]$.

LSCFM originally used in biology and life sciences to study cells for directly investigating the distribution of a fluorescence-tagged biologically active structure [29] allows studying the fragmentation process. By incorporation of a fluorescent dye into the supports the distribution of the fragments of the support can be measured in the growing and expanding particles within a few minutes.

\section{Results and discussion}

\section{Synthesis of the organic supports}

To show the applicability of videomicroscopy as a tool to compare different catalysts at the same time, three organic supports as carriers for a metallocene catalyst $\left(\mathrm{Me}_{2} \mathrm{Si}(2 \mathrm{MeBenz} \mathrm{Ind})_{2} \mathrm{ZrCl}_{2}\right)$ were prepared. Polystyrene (PS) [14] or nano-sized latex particles [13] with poly(ethylene oxide) (PEO) chains on their surfaces were used as carriers for the metallocene catalyst. Due to the nucleophilic character of the ether groups, the methylaluminoxane (MAO) activated metallocene complexes are immobilised by non-covalent interactions [12,13]. Especially, nano-sized $(100-150 \mathrm{~nm})$ latex particles have been proposed as suitable supports for metallocenes as they fragment completely within the final product during the polymerisation reaction, as shown by transmission electron microscopy and fluorescence microscopy $[13,30]$.

The support for catalyst K-1 (Scheme 1) consists of a linear PS chain functionalised with PEO for immobilizing the active metallocene catalyst and with cyclopentadiene (CP) for allowing reversible network formation by a Diels-Alder reaction [31]. This support was proven to be a suitable carrier for metallocene catalysts in olefin polymerisation as it shows good activity in the ethylene polymerisation and PE particles with high bulk densities were obtained.

The support for catalyst K-2 (Scheme 2) was also functionalised with PEO chains and CP units; however, this support consists of latex particles prepared by emulsion polymerisation [14]. In the cases of K-2 the support is aggregated not only by DielsAlder reactions between different cyclopentadienyl units but also non-covalently due to the interaction of the polar surfaces of the particles with MAO.

As a third example, latex particles (Scheme 3 ) surface-functionalised only with PEO were applied as supports to obtain catalyst K-3. In this approach, PS-PEO block copolymers were used as surfactants in the emulsion polymerisation process [13]. 
The latex particles (primary particles) are only physically aggregated by polar interactions of the ether groups of the surfactant with MAO.

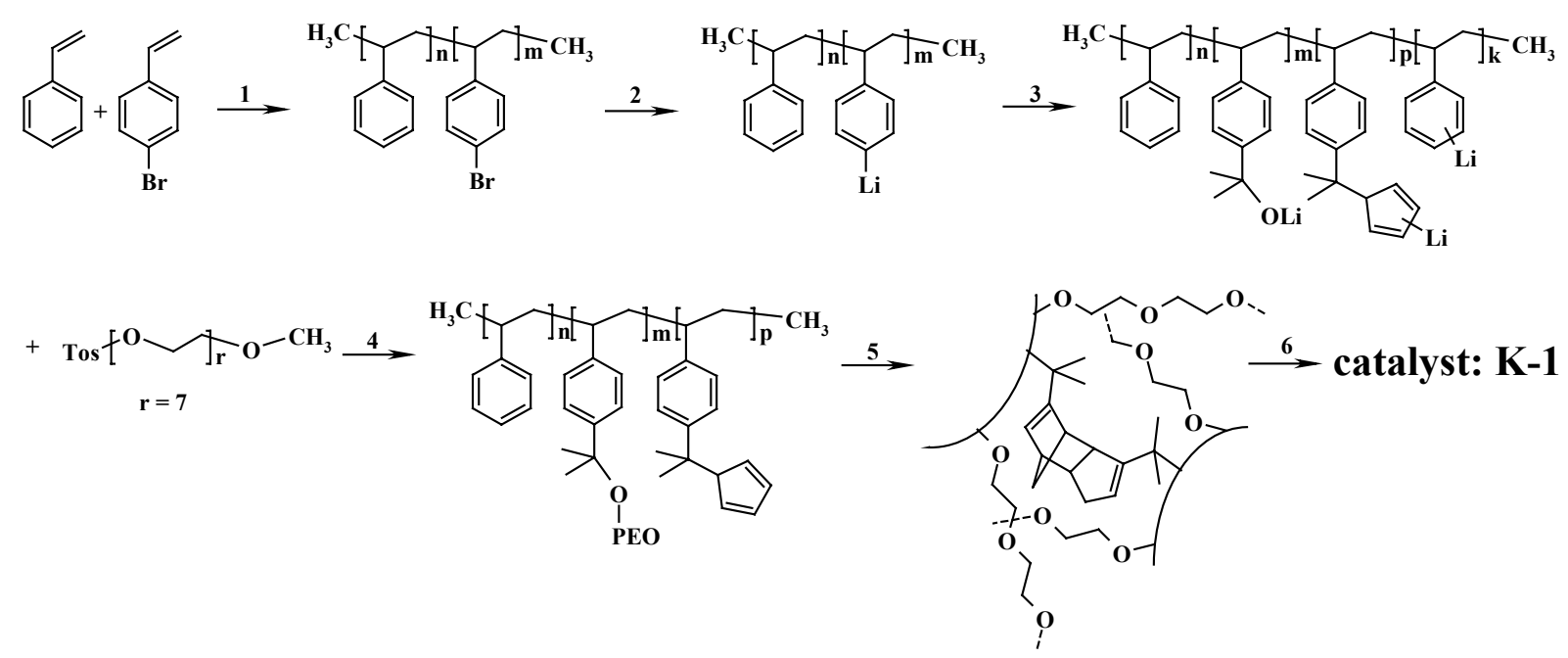

Scheme 1. Preparation of polystyrene functionalised with PEO chains and crosslinked by $\mathrm{CP}$ and the preparation of catalyst $\mathrm{K}-1$. 1: Azoisobutyronitrile, toluene, $70^{\circ} \mathrm{C}, 24 \mathrm{~h}$; 2: t-BuLi, tetrahydrofuran (THF), $-78^{\circ} \mathrm{C}, 10 \mathrm{~min}$; 3: acetone, dimethylfulvene, THF, $-78^{\circ} \mathrm{C}, 10 \mathrm{~min} ; 4: \mathrm{THF},-78^{\circ} \mathrm{C}, 1 \mathrm{~h}$; 5 : toluene, $85^{\circ} \mathrm{C}, 72 \mathrm{~h} ; 6$ : $\mathrm{Me}_{2} \mathrm{Si}-$ (2MeBenzInd) ${ }_{2} \mathrm{ZrCl}_{2}$, MAO

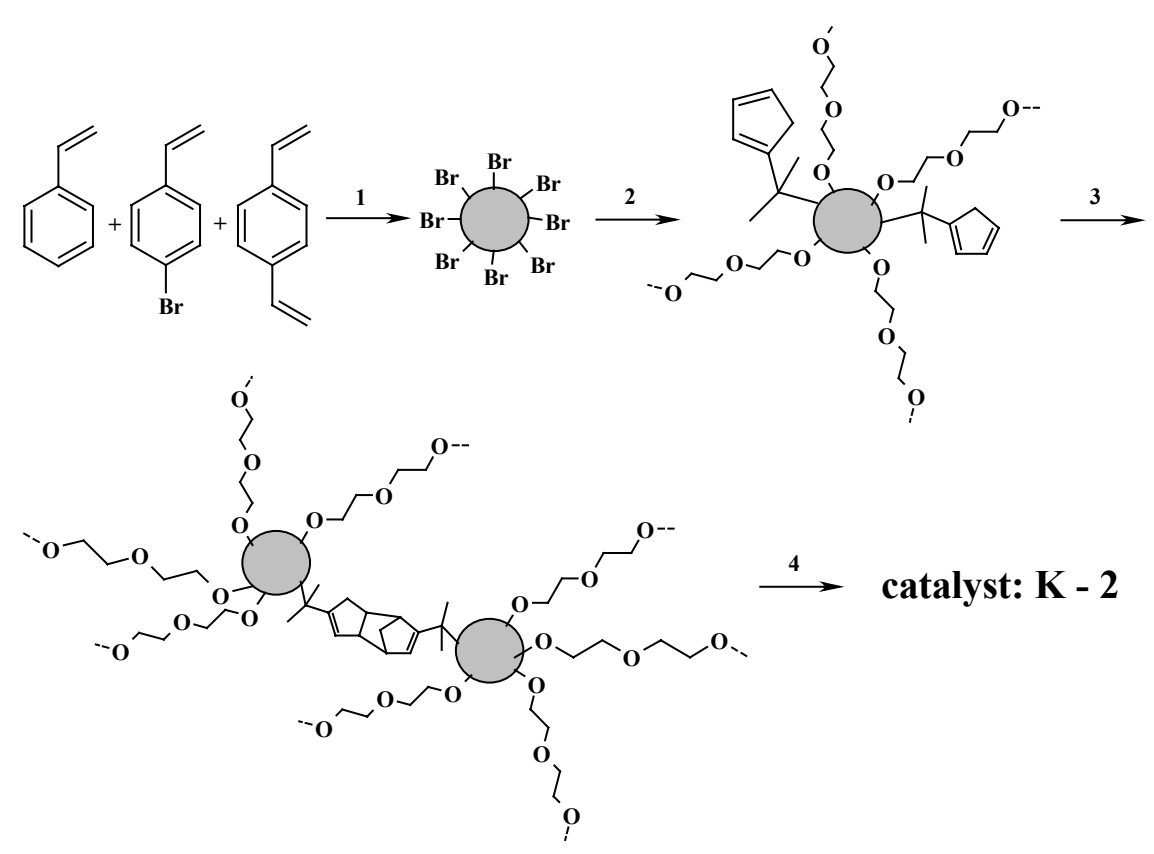

Scheme 2. Preparation of nano-sized polystyrene beads functionalised with PEO and crosslinked by CP and preparation of catalyst K-2. 1: Sodium dodecyl sulfate, distilled water, $\mathrm{K}_{2} \mathrm{~S}_{2} \mathrm{O}_{8}, 72^{\circ} \mathrm{C}$; 2: t-BuLi, acetone, dimethylfulvene, TosPEO-monomethyl ether, THF, $-78^{\circ} \mathrm{C}$; 3 : toluene, $85^{\circ} \mathrm{C}, 72 \mathrm{~h} ; 4: \mathrm{Me}_{2} \mathrm{Si}(2 \mathrm{MeBenzlnd})_{2} \mathrm{ZrCl}_{2}, \mathrm{MAO}$

All three catalyst systems were separately investigated in identical polymerisation experiments (Tab. 1). The catalyst K-3 showed much higher activity than the previous two catalysts $\mathrm{K}-1$ and $\mathrm{K}-2$. This can be explained by a faster fragmentation of the 
non-covalently crosslinked particles in comparison to the reversible network formed by covalent bonds in the Diels-Alder reactions. In all cases the polyethylene (PE) was obtained as spherical beads (size $0.2-0.8 \mu \mathrm{m}$ ) and no dust particles were observed, which means that non-covalent bonding between PEO and metallocene complexes was sufficient to immobilise the metallocene catalyst. Furthermore, the non-covalent interaction between the different latex particles in the case of K-3 is strong enough to allow for a controlled fragmentation process, which is indicated by a high bulk density (350 - $400 \mathrm{~g} / \mathrm{l})$. (Fluffy material is obtained if the interaction is too weak [12].)

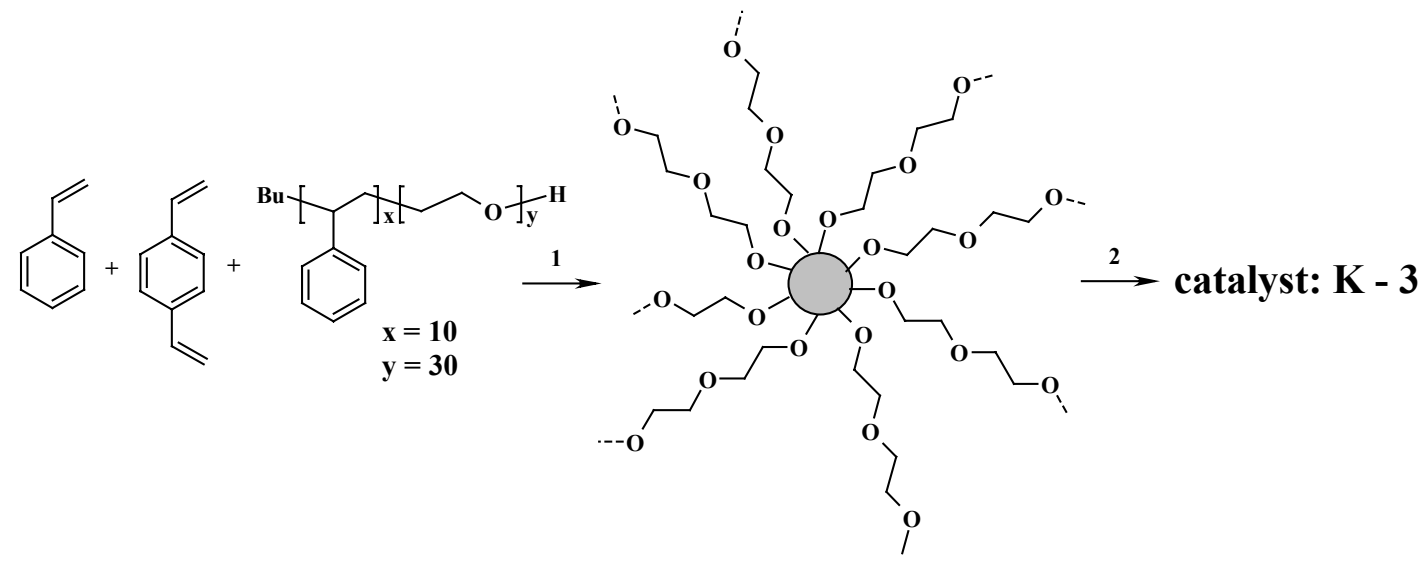

Scheme 3. Preparation of nano-sized polystyrene particle functionalised with PEO and preparation of catalyst K-3 [22]. 1: Distilled water, $\mathrm{K}_{2} \mathrm{~S}_{2} \mathrm{O}_{8}, 72^{\circ} \mathrm{C} ; 2$ : $\mathrm{Me}_{2} \mathrm{Si}(2 \mathrm{Me}-$ BenzInd) $)_{2} \mathrm{ZrCl}_{2}$, MAO

Tab. 1. Polymerisation of ethylene by metallocene catalysts supported on different organic carriers (reaction condition: 1 I autoclave, isobutene $400 \mathrm{ml}$, ethylene pressure 40 bar, $70^{\circ} \mathrm{C}$ )

\begin{tabular}{ccccccc}
\hline Run & Catalyst & $\begin{array}{c}\text { Zr/cat } \\
\text { in } \\
\mu \mathrm{mol} / \mathrm{g}\end{array}$ & $\begin{array}{c}\mathrm{MAO} / \mathrm{Zr} \\
(\mathrm{mol} / \mathrm{mol})\end{array}$ & $\begin{array}{c}\text { Polym. time } \\
\text { in min }\end{array}$ & $\begin{array}{c}\text { Activity in } \\
\mathrm{kg} \mathrm{PE} /(\mathrm{mol} \\
\mathrm{Zr} \cdot \mathrm{h} \cdot \mathrm{bar})\end{array}$ & $\begin{array}{c}\text { Productivity in } \\
\mathrm{gPE} /(\mathrm{g} \mathrm{cat} \cdot \mathrm{h})\end{array}$ \\
\hline 1 & $\mathrm{~K}-1$ & 36 & 300 & 60 & 770 & 830 \\
2 & $\mathrm{~K}-2$ & 36 & 300 & 60 & 820 & 920 \\
3 & $\mathrm{~K}-3$ & 36 & 300 & 60 & 1050 & 1400
\end{tabular}

\section{Videomicroscopy}

After having shown that all of the three catalyst systems are able to polymerise ethylene with a high activity and productivity, their reactivity was directly compared in a single experiment by videomicroscopy. The videomicroscopy equipment consists of an autoclave provided of a glass window and a connection to the vacuum line and the monomer supply. The autoclave is located under a microscope connected to a high-resolution digital camera, which enables to take a picture of the growing particles located on the plate. Pictures are taken every $20 \mathrm{~s}$ and recorded with a computer. A more detailed description of the equipment and the image processing technique can be found in ref. [28]. 
The same amounts of catalysts $\mathrm{K}-1, \mathrm{~K}-2$ and $\mathrm{K}-3$ were placed on the plate inside the autoclave by means of a glove-box. The three catalysts were polymerised at the same time allowing direct comparison of the three systems.

\section{Click here to see video 1 (8.2 MB)}

Video 1. Polymerisation of ethylene by using 3 different supported catalysts

(a)
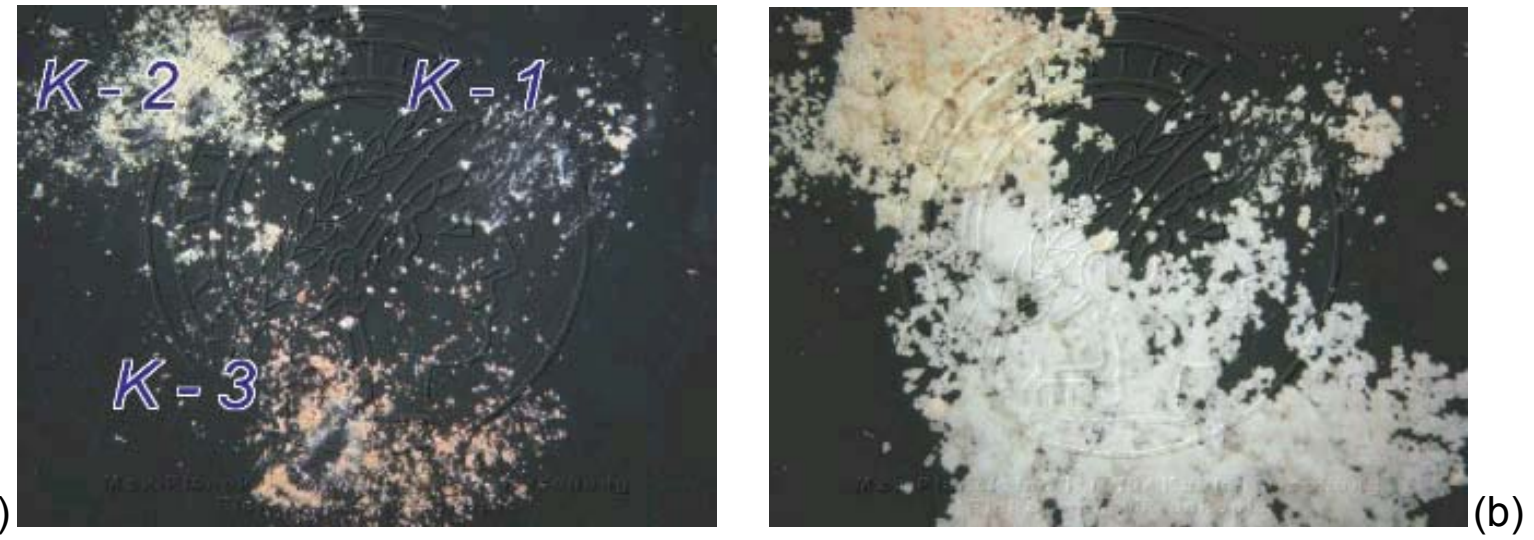

Fig. 1. Two images taken (a) at the beginning and (b) at the end of the polymerisation using three different supported catalysts (from video 1)

Video 1 shows the movie of ethylene polymerization by using the three different catalysts $\mathrm{K}-1, \mathrm{~K}-2, \mathrm{~K}-3$ under the same conditions. All three catalysts have almost the same metallocene loading. Quality of the ethylene or influence of eventually present moisture or oxygen should not play an important role for evaluation of the process, as the conditions for each catalyst are equal. At the beginning of polymerisation the catalyst K-3 was much more active than the two other catalysts and at the end of the polymerisation the polyethylene produced by K-3 almost occupied the screen of the videomicroscope (Fig. 1). The catalyst K-2 shows a lower reactivity than K-3 but starts to polymerise as well directly from the beginning. The catalyst $\mathrm{K}-1$ seems to be nearly inactive at the beginning, however, after a short period the catalyst activity increased, indicating an induction period.

This qualitative result is in accordance with those obtained by slurry polymerisation reported in Tab. 1. In fact, also in this case catalyst K-3 shows the highest activity.

But more relevant is the possibility to use videomicroscopy to study single-particle kinetics. As already described [25], it is possible to follow simultaneously the individual behaviour of a large number of single catalyst particles during the whole polymerisation and create mathematical models based on quantitative results.

Therefore, we synthesised a pyridine and PEO containing support by using vinylpyridine as monomer and oligo(ethylene oxide) containing Lutensol AT50 (BASF AG) as emulsifier [30,32]. These particles (size: $120 \mathrm{~nm}$ ) were loaded with $\mathrm{Me}_{2} \mathrm{Si}-$ (2MeBenzlnd) ${ }_{2} \mathrm{ZrCl}_{2}(30 \mu \mathrm{mol} \mathrm{Zr} / \mathrm{g}$ cat) to result K-4. Hence, K-4 was polymerised at $50^{\circ} \mathrm{C}$ and 3 bar ethylene to study single-particle kinetics (Video 2).

As an evaluation of video 2, Fig. 2 shows two snapshots taken after 0 (a) and 250 min (b) of polymerisation. From Fig. 2a, it can be seen that the initial particles present different size and shape resulting in a different growth extent. The initial particle 
shape was not maintained in all cases. It must be pointed out that not all particles are suitable for image processing because they are not isolated. A question arises from this observation: what is a single particle in this system? Only the smallest and isolated grains were assigned a number (Fig. 2) and processed to give a diagram of the particle expansion in terms of equivalent circle diameter (ECD) as a function of polymerisation time.

Click here to see video 2 (8.2 MB)

Video 2. Polymerisation of ethylene using $\mathrm{K}-4$ for evaluation of the polymerisation kinetics

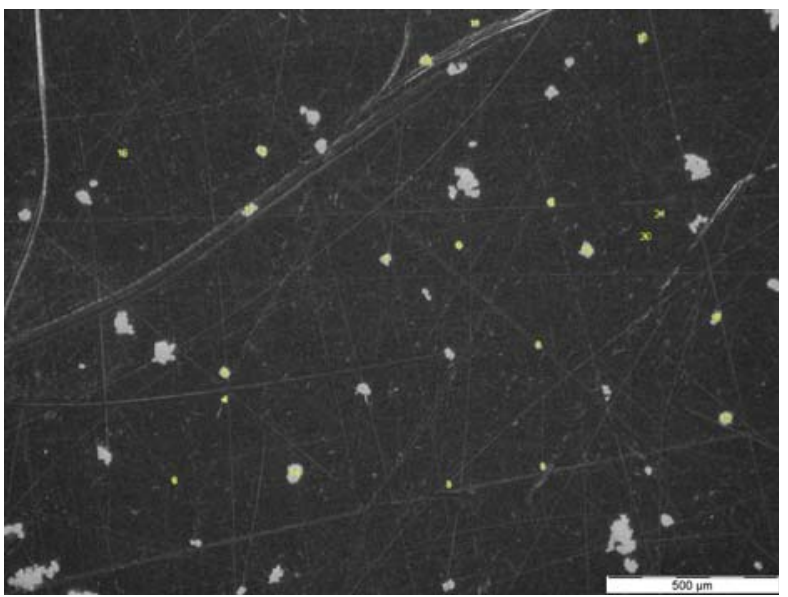

(a)

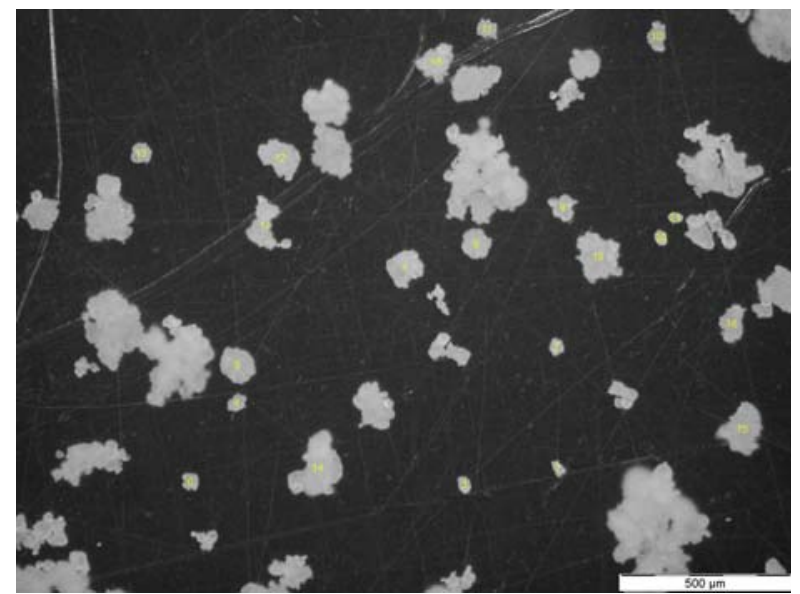

(b)

Fig. 2. Snapshots after (a) 0 and (b) 250 min of polymerisation with $\mathrm{K}-4$ at $50^{\circ} \mathrm{C}$ and 3 bar ethylene

As an example, Fig. 3 shows the ECD versus time of a few representative particles whose numbers correspond to those in Fig. 2. The particle growth is very quick in the first $10 \mathrm{~min}$ (initial steep slope in the ECD curves) of polymerisation and slows down with time (milder slope already after $15 \mathrm{~min}$ ). A further differentiation of the particle volume growth as a function of time would show a maximum corresponding with the steepest slope in the ECD diagram, as already shown [28]. This can be interpreted as a maximum in the particle growth rate. It must be also noted that smaller particles produce polymer particles with a relatively smaller final diameter. For instance particle 20 presents an initial ECD of $15 \mu \mathrm{m}$ and a final one of $30 \mu \mathrm{m}$ ( $200 \%$ growth), whereas particle 14 increases from a size of $50 \mu \mathrm{m}$ to $150 \mu \mathrm{m}$ (300\% growth).

Finally, in contrast to what was observed for silica-supported systems [25], no induction period is present in this case. This may be due to the fact that latex supports are less hard than silica and expand immediately after exposure to monomer gas.

\section{Visualisation of the fragmentation of organic supports via scanning confocal fluorescence microscopy (LSCFM)}

To study the fragmentation of the support and the distribution in the polyolefin product particle via LSCFM the carrier has to be tagged by a fluorescent dye. 
Recently, we have shown that perylene dyes are stable under the polymerisation conditions and not destroyed by the very reactive aluminium compounds or interfering with the catalyst system [33].

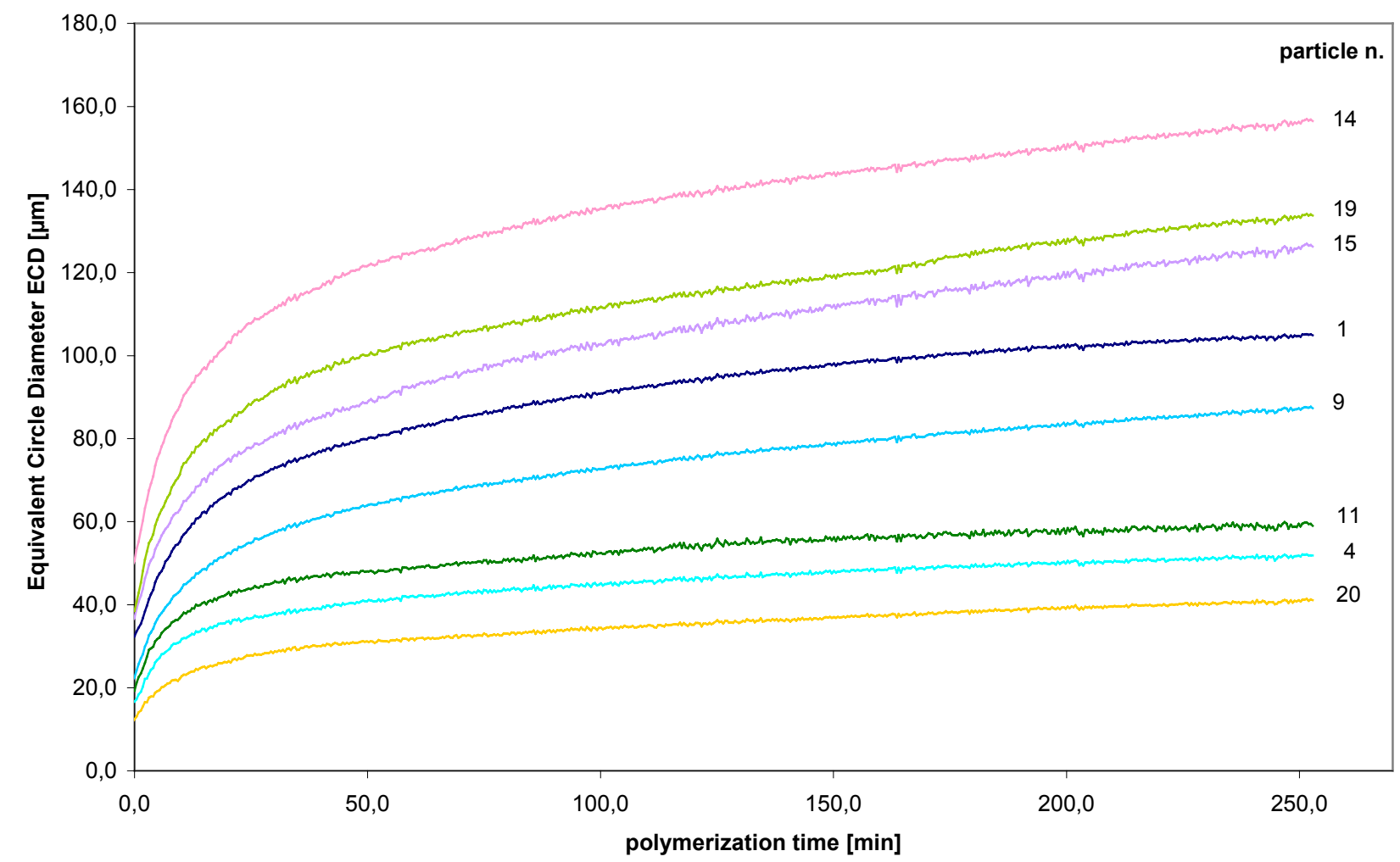

Fig. 3. Equivalent circle diameter (ECD) as a function of polymerisation time for the polymerization of ethylene with $\mathrm{K}-4$ at $50^{\circ} \mathrm{C}$ and 3 bar

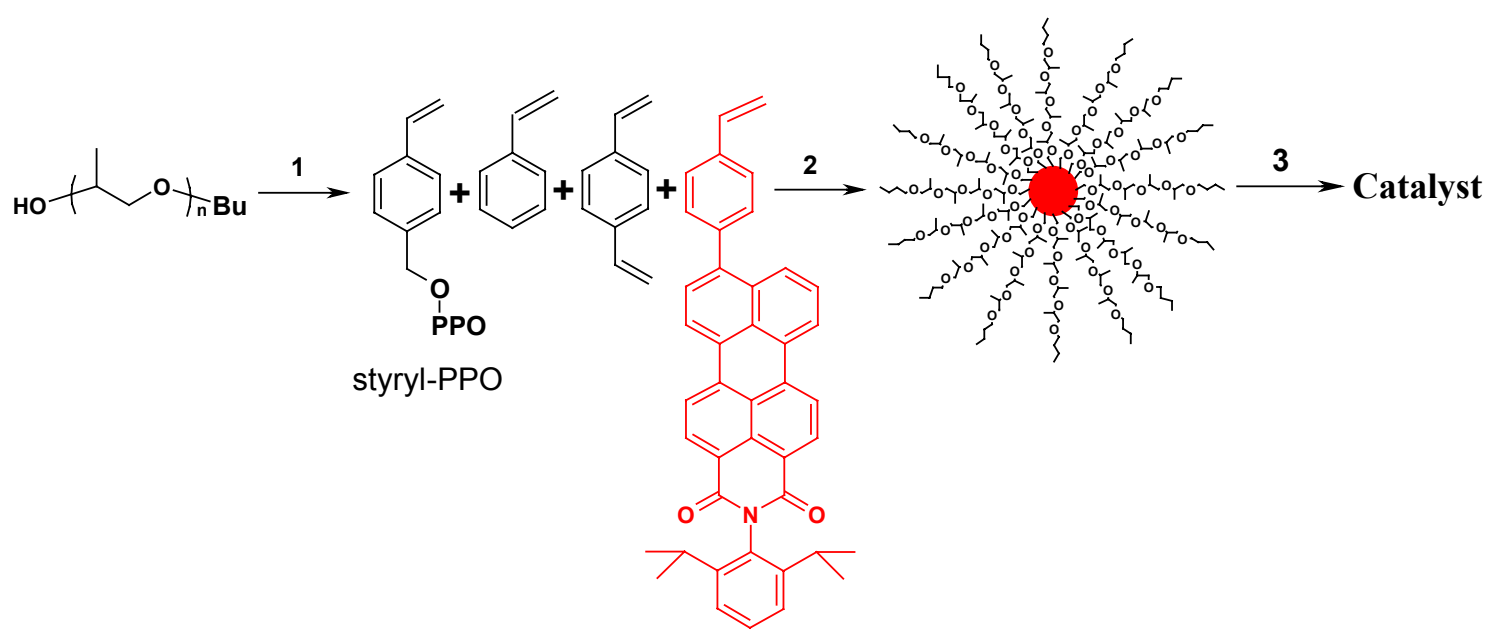

Scheme 4. Preparation of catalyst supported on nano-sized PS beads functionalised with poly(propylene oxide) (PPO) and tagged with a dye [16]. 1: $\mathrm{NaH}, \mathrm{THF}, 24^{\circ} \mathrm{C}$, $1 \mathrm{~h}$, 4-chloromethylstyrene; 2 : Sodium dodecyl sulfate, distilled water, $\mathrm{K}_{2} \mathrm{~S}_{2} \mathrm{O}_{8}, 72^{\circ} \mathrm{C}$, ultrasonification 5 min; 3: $\mathrm{Me}_{2} \mathrm{Si}(2 \mathrm{MeBenz} I n d)_{2} \mathrm{ZrCl}_{2}, \mathrm{MAO}$

Therefore, we have synthesised latex particles functionalised with PPO chains on the surface and tagged with a perylenemonoimide dye by miniemulsion polymerisation 
(Scheme 4) according to a procedure described in ref. [15]. The PS beads were functionalised with different concentrations of PPO (catalyst A $0.5 \mathrm{~mol}-\%$ and catalyst B $10 \mathrm{~mol}-\%$ of styryl-PPO, PPO chain length $\approx 2200$ ). The supported catalyst was prepared by the same procedure as described in a previous paper [16].

LSCFM allows for an optical sectioning of the particles and measuring the fluorescence distribution in different layers without slicing the particle. Fig. 4 shows a set of confocal fluorescence images and in magnification the middle layer of one catalyst bead functionalised with $10 \%$ of styryl-PPO (catalyst B). The fluorescence images show a homogeneous bright red colour within the supported catalysts indicating that the perylene dye is perfectly dispersed.

By using these supported catalysts, ethylene polymerisations were carried out under the same reaction condition of 40 bar ethylene pressure and $70^{\circ} \mathrm{C}$ polymerisation temperature. Tab. 2 shows the catalyst activity and the bulk density of PE obtained after polymerisation times of 5,15 and 60 min.

(A)
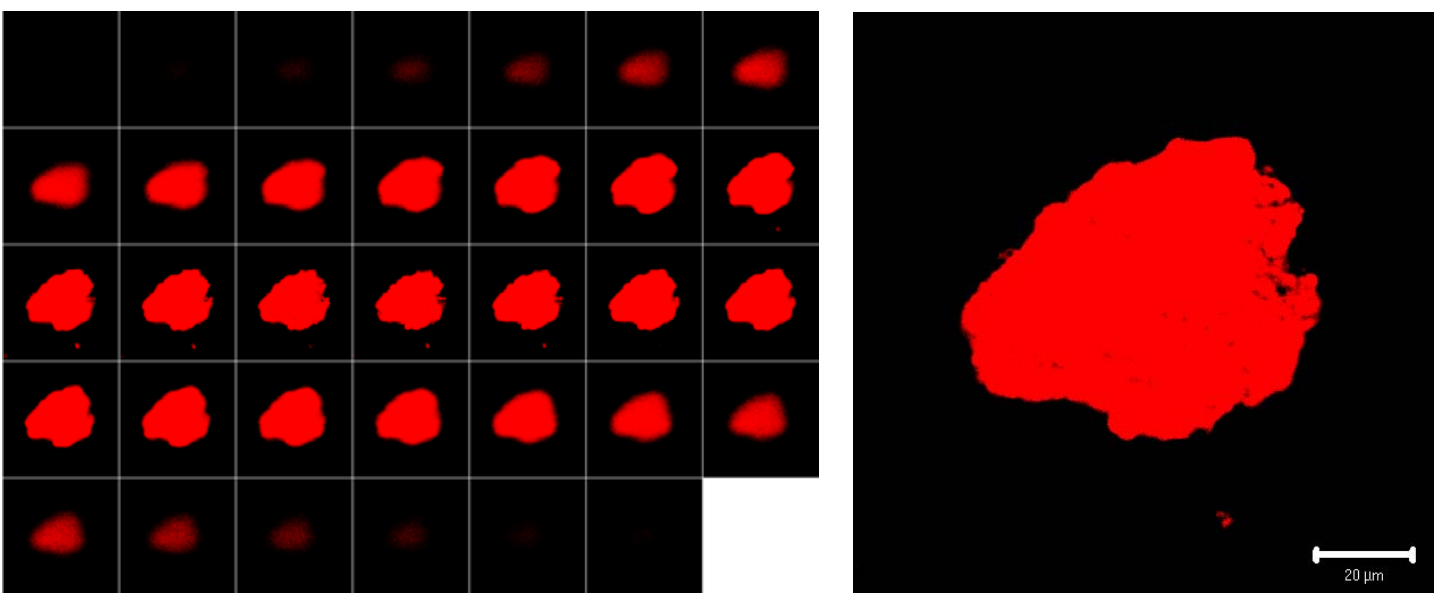

(B)

Fig. 4. Confocal fluorescence slice images of catalyst A prepared with $0.5 \mathrm{~mol}-\%$ styryl-PPO. (A) Complete set of images recorded, (B) magnification of the middle layer (objective - plan Neofluar 10; wavelength - $488 \mathrm{~nm} ; 70 \%$ transmission; scale bar $-20 \mu \mathrm{m})$

Tab. 2. Polymerisation of ethylene by the metallocene catalyst: PPO-functionalised support tagged with a perylene dye / $\mathrm{Me}_{2} \mathrm{Si}(2 \mathrm{MeBenz} / \mathrm{nd})_{2} \mathrm{ZrCl}_{2} / \mathrm{MAO}$ (reaction condition: in a $1 \mathrm{I}$ autoclave, isobutene $400 \mathrm{ml}$, ethylene pressure $40 \mathrm{bar}, 70^{\circ} \mathrm{C}, 41$ $\mu \mathrm{mol} Z \mathrm{r} / \mathrm{g}$ cat, $\mathrm{MAO} / \mathrm{Zr}=350$, catalyst $17 \mathrm{mg}$

\begin{tabular}{cccccc}
\hline Run & $\begin{array}{c}\text { Catalyst } \\
\text { (mol-\% of PPO) }\end{array}$ & $\begin{array}{c}\text { Polym. time } \\
\text { in min }\end{array}$ & $\begin{array}{c}\text { Activity in } \\
\mathrm{kg} \mathrm{PE/(mol} \\
\text { Zr·h·bar) }\end{array}$ & $\begin{array}{c}\text { Productivity in } \\
\text { g PE/(g cat } h)\end{array}$ & $\begin{array}{c}\text { Bulk density } \\
\text { in g/l }\end{array}$ \\
\hline 1 & A (0.5) & 5 & 3580 & 4750 & 200 \\
2 & A (0.5) & 15 & 3450 & 4650 & 220 \\
3 & A (0.5) & 60 & 2970 & 4120 & 280 \\
4 & B (10) & 5 & 2050 & 3210 & 300 \\
5 & B (10) & 15 & 1860 & 2740 & 350 \\
6 & B (10) & 60 & 1250 & 1770 & 430
\end{tabular}


Similar to our previous results [16], the concentration of the functional group on the PS beads influenced the catalyst activity. The supported catalyst prepared by the PS beads with lower concentration of PPO showed higher activity but lower bulk densities then the one with the higher concentration of PPO. This result suggests that in the case of the PS beads with low PPO concentration on the support, the interaction of PPO chains and MAO / metallocene is much weaker and the fragmentation faster.

To confirm this fragmentation behaviour of the catalysts, polymerisations were performed with different reaction times $(5,15$ or $60 \mathrm{~min})$. PE particles obtained from each reaction were isolated and the distribution of the fluorescent dye within the single PE particle measured by LSCFM.

The single PE particles displayed different fluorescence distributions depending on the catalyst A and B. Fig. 5 and Fig. 6 present confocal fluorescence images (middle layer) obtained for the different systems. In the case of PE particles prepared by the supported catalyst A containing the lower concentration $(0.5 \mathrm{~mol}-\%)$ of PPO, the fluorescence images (Fig. 5) show many small and red-coloured spots already dispersed homogeneously after $5 \mathrm{~min}$ of polymerisation. This indicates a very fast fragmentation of the catalyst.

On the other hand, in the case of PE produced by the supported catalyst $B$ containing the higher concentration (10 mol-\%) of PPO, the fluorescence image revealed that after 5 min polymerisation the fragmentation is still very incomplete. There are a lot of extensive fluorescent areas visible (Fig. 6A). Remarkably already from the beginning of the polymerisation fragmentation seems to occur inside the support indicated by the dark areas between the fluorescent parts. This is in contrast to the observations in silica-supported systems where the fragmentation starts from the outside of the catalyst particle. However, it confirms the kinetic investigations by the videomicroscopy described above. Even after $15 \mathrm{~min}$ of polymerisation (Fig. 6B), bright red spots of the supported catalyst are present within the whole PE particle but have already become much smaller and much more dispersed.

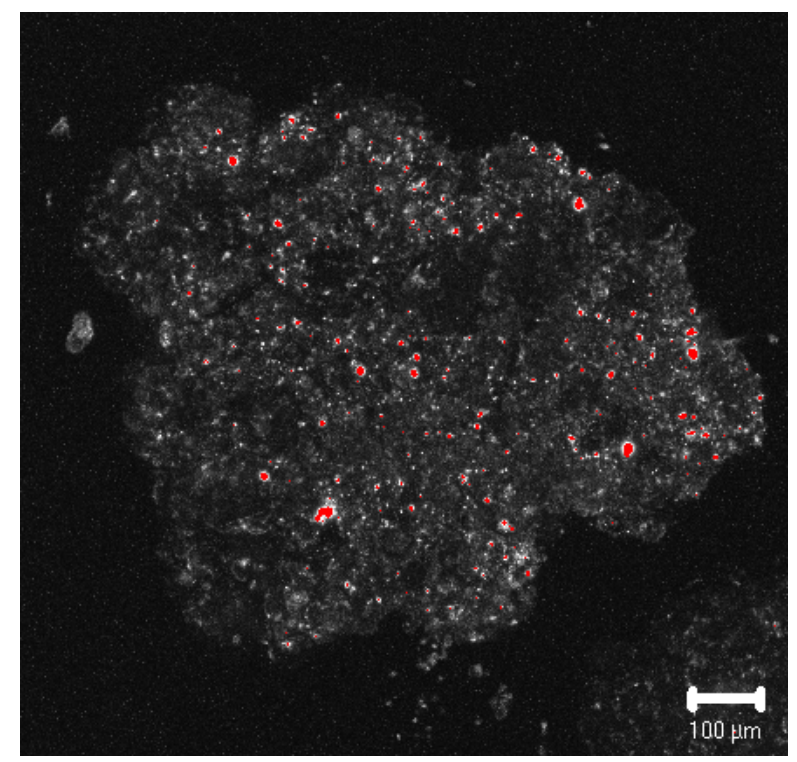

Fig. 5. Confocal fluorescence middle slice images of $\mathrm{PE}$ by catalyst $\mathrm{A}(0.5$ mol-\% of PPO): PE particle from run 1. Stack size - 651.3 x $651.3 \mu \mathrm{m}$; pixel time - $1.76 \mu$ s; objective - plan Neofluar 20X; wavelength - $488 \mathrm{~nm} ; 70 \%$ transmittance; scale bar - $100 \mu \mathrm{m}$

These results confirm our assumption that the content of polar groups enhances the interactions between the latex particles and that with increasing amount of ether 
groups the fragmentation becomes much slower. This offers the opportunity to easily control the fragmentation process by the degree of surface functionalisation of the latex particles.

For a better illustration LSCFM offers the opportunity to combine the different images of the layers and to transform them into a movie showing a $3 \mathrm{D}$ visualisation of the fluorescence distribution. To prove this we show the 3D movies of two PE particles obtained in different experiments. Immediately one can recognise the distribution of the support within the product particle and compare with other measurements.

It can be stated that with LCSFM in a short time (measuring one particle and gaining the 3D images takes less than $5 \mathrm{~min}$ ) much information about the fragmentation of the catalyst can be gained. A fast comparison of different catalysts can be performed. This should allow for a much faster evaluation of suitable supports, as fragmentation is a decisive property for new carrier materials.

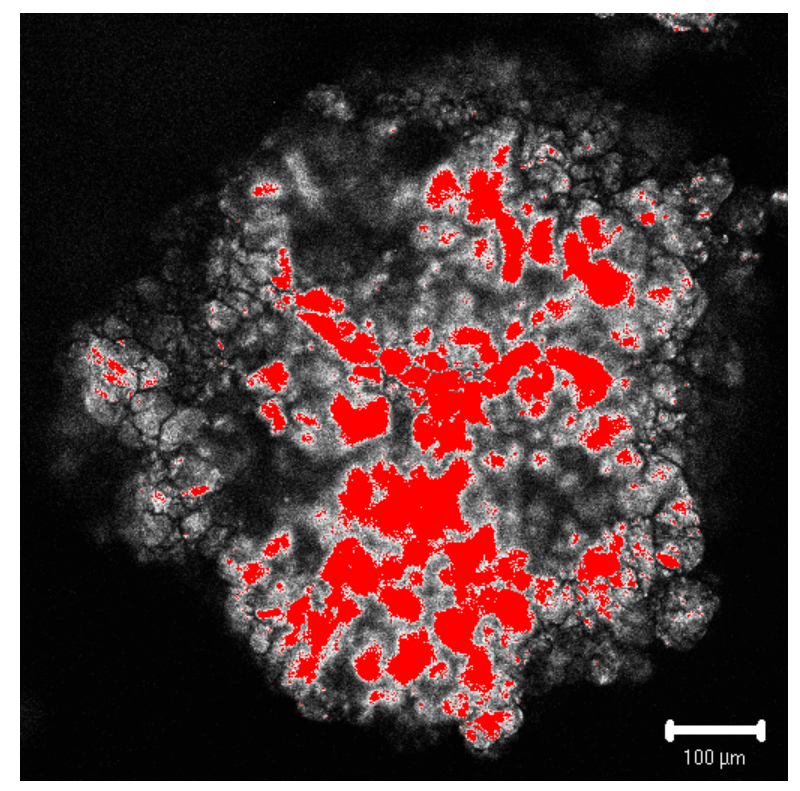

(A)

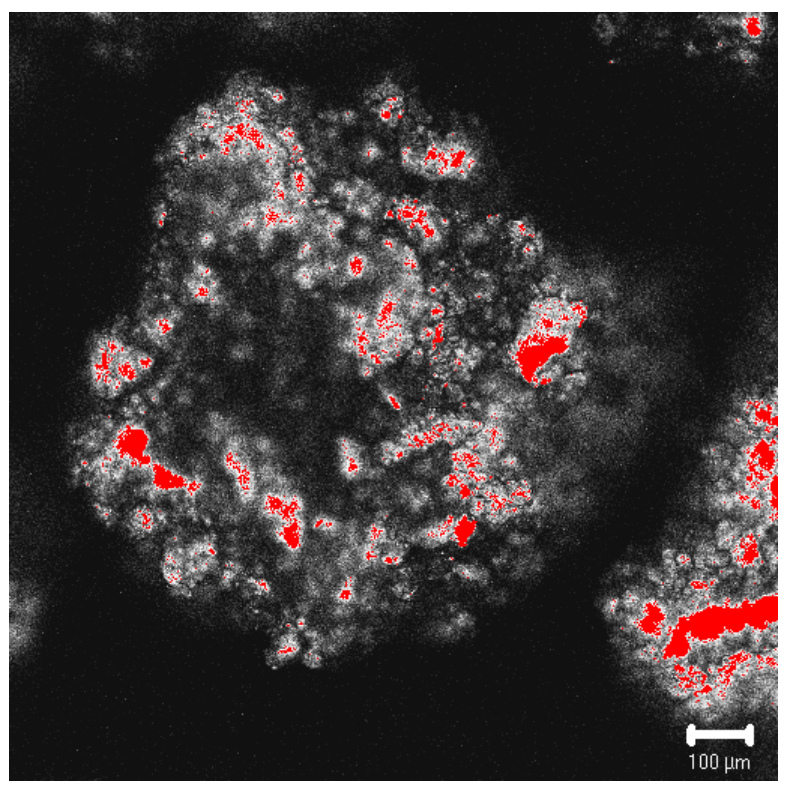

(B)

Fig. 6. Confocal fluorescence middle slice images of polyethylene (PE) by catalyst $B$ (10 mol-\% of PPO): (A) PE particle from run 4, (B) PE particle from run 5. Stack size -651.3 x $651.3 \mu \mathrm{m}$; pixel time - $1.76 \mu \mathrm{s}$; objective - plan Neofluar 20X; wavelength $-488 \mathrm{~nm} ; 70 \%$ transmittance; scale bars $-100 \mu \mathrm{m}$

(A) Click here to see a 3D image (Video 3; $5.0 \mathrm{MB}$ ) of a single PE particle (run 1)

(B) Click here to see a 3D image (Video 4; $5.0 \mathrm{MB}$ ) of a single PE particle (run 4)

Videos 3 and 4. $3 \mathrm{D}$ images of single PE particles: $(A)$ from run 1 and $(B)$ from run 4. Stack size - $651.3 \times 651.3 \times 630.0 \mu \mathrm{m}$; pixel time - $1.76 \mu \mathrm{s}$; objective - plan Neofluar 20X; wavelength $-488 \mathrm{~nm} ; 70 \%$ transmittance

\section{Conclusion}

It has been demonstrated that optical methods can be very fast and helpful tools in elucidating the polymerisation process of metallocenes loaded on different supports. 
It was shown that videomicroscopy allows for the direct comparison of the polymerisation behaviour of different catalysts under identical conditions. This was demonstrated for different catalysts based on differently functionalised organic supports. Even if this method is only qualitative, it has the advantage that the effect of experimental uncertainties such as differences in the quality of the used gases and activators can be excluded.

To get a more detailed evaluation of the polymerisation process it is possible to apply videomicroscopy also for studying the growth of single particles and to perform single-grain kinetics. This offers the basis to develop kinetic models for the polymerisation process of catalysts supported on organic materials. Differences to already described inorganic supports can be expected as due to the swellability of organic supports in organic solvents and in the monomer a different diffusion behaviour decisive for the polymerisation rate should occur.

As second optical tool - laser scanning confocal fluorescence - was applied. It was proven that this method allows in the case of fluorescence-tagged supports a very rapid investigation of the fragmentation process. This method is much faster than electron microscopy, however, the resolution of this method is limited by the wavelength of the applied laser and, therefore, is at least two orders of magnitude lower than for electron microscopy (LSCFM $\approx 500 \mathrm{~nm}, \mathrm{EM} \approx 5 \mathrm{~nm}$ ). However, due to the rapid measurements many grains of one experiment can be studied in a short time and a statistic evaluation of the fragmentation process performed. It also offers the chance to study more systematically the dependence of the fragmentation on pressure or temperature. Herein we have only investigated organic supports; an extension to other organic supports as Merryfield resins and to inorganic supports as silica is currently carried out. Therefore, this method can be considered as a compromise between integral methods as calorimetry or videomicroscopy and the singlegrain methods as electron microscopy.

\section{Experimental part}

\section{Materials}

Ethylene (BASF AG, Ludwigshafen) was purified by passage through columns of BASF R3-15 deoxygenation catalyst and 4- $\AA$ molecular sieve. Purification of isobutane was achieved with Oxisorb and Hydrosorb gas purification systems. The $\mathrm{Me}_{2} \mathrm{Si}(2 \mathrm{MeBenzInd})_{2} \mathrm{ZrCl}_{2}$ metallocene (Basell Polyolefins), MAO (10 wt.-\% in toluene) (Witco, Germany), and triisobutylaluminium (TIBA) (1.0 M in hexane, Fluka) were used without further purification.

\section{Preparation of supports and supporting of catalyst}

Preparation of the supports was published elsewhere [13-15,30,32]. The PPOfunctionalised support $(52 \mathrm{mg})$ was mixed with a solution of MAO $(2 \mathrm{ml})$ in toluene and stirred overnight to remove traces of water. The amount of MAO depended on the desired activation. A solution of $\mathrm{Me}_{2} \mathrm{Si}(2 \mathrm{MeBenz} \mathrm{nd})_{2} \mathrm{ZrCl}_{2}$ and $\mathrm{MAO}(1.5 \mathrm{ml})$ was added to the MAO / polymer support mixture. After $1 \mathrm{~h}$, the suspended supported catalyst was dried in vacuum. 
Polymerisation procedure and polyethylene characterisation

The reactor (1 I Büchi stainless steel, equipped with a stirrer) was purged with argon and charged with $400 \mathrm{ml}$ isobutane and $5 \mathrm{ml}$ TIBA. Ethylene pressure of 40 bar was applied and the reactor heated to $70^{\circ} \mathrm{C}$. The catalyst was injected with argon into the reactor through the pressure lock without further activation with MAO. Each PE particle measured by laser scanning confocal fluorescence microscopy at room temperature on a Zeiss - ConfoCor2 combi system equipped with a 10, 20 and $40 \mathrm{x}$ Fluar objective. The standard filter settings for fluorescence excitation and emission were used. Stack size - 651.3 x $651.3 \mu \mathrm{m}$; pixel time - $1.76 \mu \mathrm{s}$; objective - plan Neofluar 10X; wavelength $-488 \mathrm{~nm} ; 70 \%$ transmission.

\section{Videomicroscopy (gas-phase polymerisation)}

The autoclave equipped with a glass window and a steel plate was evacuated over night at $70^{\circ} \mathrm{C}$ and loaded under inert atmosphere. The catalyst was spread over a steel plate; the reactor was then placed under the microscope bearing the camera and connected to the ethylene line. The picture sequence was started ( 1 snapshot / $20 \mathrm{~s}$ ) and the monomer was supplied. Ethylene was polymerised for $250 \mathrm{~min}$. Windows ${ }^{\circledR}$-based image processing was carried out using analySIS Pro ${ }^{\circledR}$ software and used to determine the projection area of the particle under study. From the projection area of the growing particles, it was possible to estimate the diameter of a circle of equivalent area (equivalent circle diameter, ECD). A detailed description of the videomicroscopy equipment and image processing can be found in ref. [28].

Acknowledgement: Donation of the metallocene by Basell Polyolefins is gratefully acknowledged.

[1] Soga, K.; Kim, H. J.; Shiono, T.; Macromol. Chem. Phys. 1994, 195, 3347.

[2] Soga, K.; Arai, T.; Nozawa, H.; Uozumi, T.; Macromol. Symp. 1995, 97, 53.

[3] Sacchi, M. C.; Zucchi, D.; Tritto, I.; Locatelli, P.; Macromol. Chem. Phys. 1995, 16, 581.

[4] Kitagawa, T.; Uozumi, T.; Soga, K.;Takata, T.; Polymer 1997, 38, 615.

[5] liskola, E. I.; Timonen, S.; Pakkanen, T. T.; Härkki, O.; Lehmus, P.; Seppälä, J. V.; Macromolecules 1997, 30, 2853.

[6] Arai, T.; Ban, H. T.; Uozumi, T.; Soga, K.; Macromol. Chem. Phys. 1997, 198, 229.

[7] Semikolenova, N.; Zakharov, V. A.; Macromol. Chem. Phys. 1997, 198, 2889.

[8] Hong, S. C.; Ban, H. T.; Kishi, N.; Uozumi, T.; Soga, K.; Macromol. Chem. Phys. 1998, 199, 1393.

[9] Alt, H. G.; Schertl, P.; Köppl, A.; J. Organomet. Chem. 1998, 568, 263.

[10] Rahiala, H.; Beurroies, I.; Eklund, T.; Hakala, K.; Gougeon, Trens, P.; Rosenholm, J. B.; J. Catal. 1999, 188, 14.

[11] Stork, M.; Koch, M.; Klapper, M.; Müllen, K.; Gregorius, H.; Rief, U.; Makromol. Chem., Rapid. Commun. 1999, 20, 210.

[12] Koch, M.; Stork, M.; Klapper, M.; Müllen, K.; Macromolecules 2000, 33, 7713. 
[13] Koch, M.; Falcou, A.; Nenov, N.; Klapper, M.; Müllen, K.; Macromol. Rapid Commun. 2001, 22, 1455.

[14] Nenov, N.; Koch, M.; Klapper, M.; Müllen, K.; Polym. Bull. 2002, 47, 391.

[15] Jang, Y. J.; Nenov, N.; Klapper, M.; Müllen, K.; Polym. Bull. 2003, 50, 343.

[16] Jang, Y. J.; Nenov, N.; Klapper, M.; Müllen, K.; Polym. Bull. 2003, 50, 351.

[17] Fink, G.; Steinmetz, B.; Zechlin, J.; Przybyla, C.; Tesche, B.; Chem. Rev. 2000, 100, 1377.

[18] Zechlin, J.; Hausschild, K.; Fink, G.; Macromol. Chem. Phys. 2000, 201, 597.

[19] Zechlin, J.; Steinmetz, B.; Tesche, B.; Fink, G.; Macromol. Chem. Phys. 2000, $201,515$.

[20] Steinmetz, B.; Zechlin, J.; Przybyla, C.; Tesche, B.; Fink, G.; Nachr. Chem. 2000, 8, 12.

[21] Przybyla, C.; Zechlin, J.; Steinmetz, B.; Tesche, B.; Fink, G.; in "Metallorganic Catalysts for Synthesis and Polymerisation", Kaminsky, W., editor; Springer, Berlin 1999, pp. 321 - 332.

[22] Knoke, S.; Korber, F.; Fink, G.; Tesche, B.; Macromol. Chem. Phys. 2003, 204, 607.

[23] Korber, F.; Hausschild, K.; Fink, G.; Macromol. Chem. Phys. 2001, 202, 3329.

[24] Korber, F.; Hausschild, K.; Winter, M.; Fink, G.; Macromol. Chem. Phys. 2001, 202, 3323.

[25] Alexiadis, A.; Andes, C.; Ferrari, D.; Korber, F.; Hauschild, K.; Bochmann, M.; Fink, G.; Macromol. Mater. Eng. 2004, 289, 457.

[26] Przybyla, C.; Weimann, B.; Fink, G.; in "Metallorganic Catalysts for Synthesis and Polymerisation", Kaminsky, W., editor; Springer, Berlin 1999, pp. 333-346, Part 2.

[27] Zöllner, K.; Reichert, K. H.; Chem. Ing. Tech. 2001, 73, 849.

[28] Knoke, S.; Ferrari, D.; Tesche, B.; Fink, G.; Angew. Chem. - Int. Ed. Engl. 2003, $42,5090$.

[29] Tsumoto, K.; Luckel, F.; Yoshikawa, K.; Biophysical Chemistry 2003, 106, 23.

[30] Klapper, M.; Jang, Y. J.; Bieber K.; Nemnich, T.; Nenov, N.; Macromol. Symp. 2004, 213, 131.

[31] Nenov, N.; Dissertation, Johannes-Gutenberg-Universität, Mainz 2003.

[32] The emulsifier Lutensol AT50 (200 mg) was dissolved in $50 \mathrm{ml}$ of distilled water with stirring for $20 \mathrm{~min}$ at $40^{\circ} \mathrm{C}$. After cooling to room temperature, styrene $(24 \mathrm{mmol}$, $2.5 \mathrm{~g})$, 4-vinylpyridine (24 mmol, $2.46 \mathrm{~g})$, divinylbenzene $(1.8 \mathrm{mmol}, 240 \mathrm{mg}$ ) and hexadecane $(209.2 \mathrm{mg}$ ) were added and the mixture was stirred for $30 \mathrm{~min}$ at 1000 $\mathrm{rpm}$ to form a microemulsion. The emulsion was then treated for $5 \mathrm{~min}$ at $75 \%$ amplitude with a sonifier in an ice bath. The formed miniemulsion was degassed by bubbling argon through it for $20 \mathrm{~min}$. The initiator V50 (105 mg) was dissolved in $5 \mathrm{ml}$ of distilled water and also degassed with argon. The miniemulsion was heated up to $70^{\circ} \mathrm{C}$ and the initiator was added. The polymerisation was run over night. The formed dispersion was filtered and dialysed with a stirring cell equipped with a polyethersulfone membrane. The latex particles were freeze-dried.

[33] Stork, M.; Herrmann, A.; Nemnich, T.; Klapper, M.; Müllen, K.; Angew. Chem. 2000, 112, 4544. 